\title{
Minimal Residual Disease Negativity
}

National Cancer Institute

\section{Source}

National Cancer Institute. Minimal Residual Disease Negativity. NCI Thesaurus. Code C124428.

Absence of residual disease based on laboratory techniques. 